\title{
Characterising the transcriptome of hypersegmented human
}

\section{neutrophils [version 1; peer review: 2 approved with}

\section{reservations]}

\author{
Eleonore Fox, Rowena Jones (D), Romit Samanta (iD), Charlotte Summers \\ Department of Medicine, University of Cambridge School of Clinical Medicine, Cambridge, CB2 0QQ, UK
}

V1 First published: $14 \operatorname{Dec} 2021,6: 343$

https://doi.org/10.12688/wellcomeopenres.17440.1

Latest published: $14 \mathrm{Dec} 2021,6: 343$

https://doi.org/10.12688/wellcomeopenres.17440.1

\section{Abstract}

Background: Mature human neutrophils are characterised by their multilobed nuclear morphology. Neutrophil hypersegmentation, a pathologic nuclear phenotype, has been described in the alveolar compartment of patients with acute respiratory distress syndrome and in several other contexts. This study aimed to characterise the transcriptional changes associated with neutrophil hypersegmentation.

Methods: A model of hypersegmentation was established by exposing healthy peripheral blood neutrophils to the angiotensin converting enzyme inhibitor (ACEi) captopril. Laser capture microdissection (LCM) was then adapted to isolate a population of hypersegmented neutrophils. Transcriptomic analysis of microdissected hypersegmented neutrophils was undertaken using ribonucleic acid (RNA) sequencing. Differential gene expression (DEG) and enrichment pathway analysis were conducted to investigate the mechanisms underlying hypersegmentation.

Results: RNA-Seq analysis revealed the transcriptomic signature of hypersegmented neutrophils, with five genes differentially expressed. VCAN, PADI4 and DUSP4 were downregulated, while LTF and PSMC4 were upregulated. Modulated pathways included histone modification, protein-DNA complex assembly and antimicrobial humoral response. The role of PADI4 was further validated using the small molecule inhibitor, $\mathrm{Cl}$-amidine.

Conclusions: Hypersegmented neutrophils display a marked transcriptomic signature, characterised by the differential expression of five genes. This study provides insights into the mechanisms underlying neutrophil hypersegmentation and describes a novel method to isolate and sequence neutrophils based on their morphologic subtype.

\section{Keywords}

Neutrophil, nuclear morphology, hypersegmentation, RNAseq

\section{Open Peer Review}

\begin{tabular}{|c|c|c|}
\hline & 1 & 2 \\
\hline version 1 & $?$ & $?$ \\
\hline 14 Dec 2021 & view & view \\
\hline
\end{tabular}

1. Sarah Walmsley , University of Edinburgh, Edinburgh, UK

2. Ravi Lokwani (D), National Institutes of Health, Bethesda, USA

Any reports and responses or comments on the article can be found at the end of the article. 
Corresponding author: Charlotte Summers (cs493@medschl.cam.ac.uk)

Author roles: Fox E: Conceptualization, Formal Analysis, Investigation, Methodology, Writing - Original Draft Preparation; Jones R: Investigation, Methodology; Samanta R: Data Curation, Formal Analysis; Summers C: Conceptualization, Formal Analysis, Funding Acquisition, Methodology, Project Administration, Resources, Supervision, Writing - Review \& Editing

Competing interests: No competing interests were disclosed.

Grant information: This work was supported by the Wellcome Trust ISSF grant to CS [204845, https://doi.org/10.35802/204845]. The work also received funding from the Cambridge NIHR Biomedical Research Centre (BRC1215-20014). The views expressed do not necessarily represent those of the National Institute for Health Research (NIHR) or the Department of Health and Social Care. The funders had no role in the study design, data collection and analysis, decision to publish, or preparation of the manuscript. The funders had no role in study design, data collection and analysis, decision to publish, or preparation of the manuscript.

Copyright: (c) 2021 Fox E et al. This is an open access article distributed under the terms of the Creative Commons Attribution License, which permits unrestricted use, distribution, and reproduction in any medium, provided the original work is properly cited.

How to cite this article: Fox E, Jones R, Samanta R and Summers C. Characterising the transcriptome of hypersegmented human neutrophils [version 1; peer review: 2 approved with reservations] Wellcome Open Research 2021, 6:343

https://doi.org/10.12688/wellcomeopenres.17440.1

First published: 14 Dec 2021, 6:343 https://doi.org/10.12688/wellcomeopenres.17440.1 


\section{Introduction}

Neutrophils are the most numerous white blood cells in humans (Rosales 2018) and the principal effectors of the innate immune system. To fulfil this role, neutrophils are able to readily migrate to sites of inflammation where they recognise, phagocytose, and kill invading microorganisms ${ }^{1}$.

Human neutrophils have a dynamic nuclear architecture. Immature (banded) neutrophils are often released into the peripheral blood during severe sepsis and have a single dumb-bell shaped nucleus. Once mature, the chromatin of human neutrophils is clustered in lobes linked to one another by dense heterochromatin filaments ${ }^{2,3}$, with on average two to four lobes. In 1904, Arneth quantified the proportion of neutrophils with each number of lobes under homeostatic conditions; he established that $5 \%$ of human neutrophils had horseshoe-shaped or indented nuclei, $35 \%$ had two lobes; $41 \%$ had three, $17 \%$ four and $\leq 2 \%$ had five lobes ${ }^{4}$. Neutrophil hypersegmentation is considered pathological, and is defined by the presence of more than $2 \%$ of cells with five lobes, or the presence of cells with six or more lobes ${ }^{2}$. The presence of hypersegmentation was previously associated with the maturation state of a neutrophil ${ }^{5}$, but, more recently, hypersegmentation has been observed in other contexts ${ }^{6}$.

The capacity of neutrophils to alter their nuclear architecture is poorly understood, and the advantages of having a multilobed nuclear morphology are unclear? ${ }^{7}$. It has been hypothesised that the multilobed phenotype increases the deformability of neutrophils and facilitates their migration through thin tissue spaces $^{8}$. Alternatively, it may enhance phagocytosis by offering a wider cytoplasmic space to engulf pathogens?. However, during acute inflammation, immature banded neutrophils released into the circulation have been shown to have similar migratory properties to those of mature, multilobed neutrophils ${ }^{10}$. Moreover, the nuclear morphology of neutrophils varies widely across mammalian species, yet they achieve similar anti-microbial tasks, suggesting this hypothesis may be incorrect ${ }^{11}$.

Juss et al. reported an increased number of hypersegmented neutrophils in the bronchoalveolar lavage of patients with acute respiratory distress syndrome (ARDS), when compared to peripheral blood neutrophils sampled from the same patients, and to peripheral blood from age/sex-matched healthy controls $^{6}$. More than $25 \%$ of the alveolar neutrophils of patients with ARDS had five or more lobes, compared to around $10 \%$ in blood neutrophils from the same patients, and around $2 \%$ in blood obtained from healthy volunteers. Neutrophil hypersegmentation has also been observed in other contexts including bacterial infection, in association with tumours, and in the lungs of patients with chronic obstructive pulmonary disease $^{12-14}$. Very little is known about the mechanisms of hypersegmentation, or the functional consequences of the chromatin rearrangement occurring during this alteration in neutrophil morphology.

Transcriptomic analysis of human neutrophils has been largely neglected. For many years it was held that the short lifespan of neutrophils, their paucity of mRNA, and their high content of endonucleases made such analyses too challenging ${ }^{15,16}$. Recent studies have demonstrated that neutrophils are multifaceted cells with an active transcriptional program amenable to whole genome analysis ${ }^{17,18}$. To permit the characterisation of the transcriptome of hypersegmented neutrophils, we combined a robust model of human neutrophil hypersegmentation with the use of laser capture microscopy (LCM) to identify and collect cells for RNA sequencing based on their morphology. Here we describe for the first time, the transcriptome of microdissected human neutrophils, identifying genes and pathways associated with hypersegmentation.

\section{Methods}

\section{Ethical considerations}

Ethical permission was granted by the Cambridge Research Ethics Committee (06/Q0108/281). All participants gave written informed consent.

\section{Isolation of human neutrophils}

Peripheral venous blood was sampled from age-matched healthy adult volunteers (no significant chronic illness or need for long-term medication) who had provided written informed consent. Participants were recruited from a bank of healthy volunteers, who volunteered to join the research blood donation programme after responding to posters placed at Addenbrooke's Hospital and the University of Cambridge. A research nurse obtained informed consent from participants between June and August 2019. Sex-disaggregated data is not available is the terms of our ethical permissions do not allow us to record this data.

Using a 19-gauge butterfly needle, two aliquots of $40 \mathrm{~mL}$ of peripheral venous blood were anticoagulated with $3.8 \%$ sodium citrate (Martindale Pharmaceuticals) and circulating neutrophils were immediately purified using discontinuous plasma-Percoll density gradient centrifugation under sterile conditions as previously described ${ }^{19}$. Neutrophil purity was routinely $>98 \%$ with eosinophils as the major contaminant. Neutrophils were immediately processed for subsequent experiments as outlined below.

\section{Neutrophil morphology analysis}

Freshly isolated neutrophils were centrifuged for 3 minutes at $300 \mathrm{rpm}$ onto polyethylene naphtalate (PEN)-membrane microscope slides (Leica Biosystems) or Polysine ${ }^{\mathrm{TM}}$ microscope slides (VWR International) using a Shandon Cytospin 3 (Shandon). Neutrophil morphology was assessed by a researcher blinded to the experimental conditions. Neutrophils were considered apoptotic if they showed dense condensation of chromatin forming a single nucleus, hypersegmented if they possessed five lobes or more, and normally lobulated if they had between two and four lobes ${ }^{4}$.

\section{Induction of hypersegmentation in primary human neutrophils}

Human neutrophils were centrifuged (Hettich Rotina, model 420r) for $5 \mathrm{~min}$ at $256 \mathrm{~g}$ and resuspended in $10 \%$ autologous serum 
(AS) in Hank's Balanced Salt Solution (HBSS) (Thermo Fisher Scientific) $\left(2.5 \times 10^{6}\right.$ cells $\left./ \mathrm{mL}\right)$ before stimulation with the following increasing captopril concentrations:0 $\mu \mathrm{M}, 10 \mu \mathrm{M}$, $30 \mu \mathrm{M}, 100 \mu \mathrm{M}, 300 \mu \mathrm{M}$ and $1000 \mu \mathrm{M}$. Plates were placed in a shaker (Eppendorf Thermomixer) at $300 \mathrm{rpm}$ at $37{ }^{\circ} \mathrm{C}$ for 3 hours. Once the optimal concentration was identified, neutrophils were incubated in HBSS supplemented with $10 \%$ AS and $300 \mu \mathrm{M}$ captopril in a shaking plate at $37{ }^{\circ} \mathrm{C}$ for $0 \mathrm{~h}, 2 \mathrm{~h}$, $4 \mathrm{~h}$ or $6 \mathrm{~h}$.

\section{Laser capture microdissection}

We adapted the laser capture microdissection (LCM) technique to identify and isolate a population of hypersegmented neutrophils for transcriptomic analysis. LCM has the capacity to separate a defined area from a heterogeneous cell population and is applicable for use on histologically stained paraffin-embedded tissues, cell smears and cytospins ${ }^{20}$. RNA sequencing was then undertaken on microdissected cells to characterise the differential gene expression profile of hypersegmented neutrophils.

The fixing and staining of neutrophil cytospins were optimised for RNA Integrity Number (RIN) preservation. Neutrophils on PEN-membrane glass slides were fixed with ice-cold $95 \%$ ethanol for $30 \mathrm{sec}$, then air-dried and stored at $-80{ }^{\circ} \mathrm{C}$ for a maximum of three days. Slides were then stained for $1 \mathrm{~min}$ with hematoxylin and dehydrated in increasing ethanol concentrations to remove any remaining moisture: $50 \%$ for $10 \mathrm{sec}, 70 \%$ for $20 \mathrm{sec}, 95 \%$ for $15 \mathrm{sec}, 100 \%$ for $25 \mathrm{sec}$ and $100 \%$ for $30 \mathrm{sec}$. Laser capture microdissection was undertaken using 63x magnification on a Leica LMD6 system (Leica, Biosystems) using the Leica LMD software V7.6 (Leica, Biosystems), which allowed for the identification and selection of 1500 neutrophils per condition (750 in duplicate), which were then collected into a $0.5 \mathrm{~mL}$ collection tube (Greiner Bio-One).

\section{RNA extraction and next generation sequencing}

Microdissected neutrophils were lysed in Buffer RLT (Qiagen) supplemented with $1 \%$ of $\beta$-mercaptoethanol ( $\beta-\mathrm{ME}$ ), and this was followed by a brief vortex to homogenise the cells before storage at $-80{ }^{\circ} \mathrm{C}$ for a maximum of three days. RNA extraction was performed according to Qiagen's RNeasy UCP Micro Kit protocol (Qiagen) including an on-column DNase digest under clean laboratory conditions. The resultant RNA was divided into two equal technical replicates for the cDNA libraries preparation. Prior to cDNA library preparation, an additional DNase incubation step was performed according to manufacturer's instructions (Heat\&Run gDNA removal kit, ArcticZymes). The SMART Seq Stranded Micro kit (Takara Bio) was optimised for cDNA library preparation, and the following workflow was undertaken. RNA was reverse-transcribed and converted to cDNA after $4 \mathrm{~min}$ of fragmentation. Illumina adapters and barcodes were added through ten cycles of polymerase chain reaction (PCR) (following the ultra-low input protocol option). The PCR products were then purified by immobilisation onto AMPure beads (Beckman Coulter Life Science), ribosomal cDNA was depleted using mammalian-specific probes, and the remaining fragments were amplified with 10 additional PCR cycles before a final purification. The resulting cDNA fragments were assessed using the DNA HS kit according to manufacturer's instructions on the Bioanalyser 2100 (Agilent). Paired-end 150 base pair (bp) sequencing was undertaken using an Illumina NovaSeq 6000 System S1 Flow Cell (Illumina) after normalisation of concentrations to the sample with the lowest concentration; $12.5 \mathrm{fM}$ per sample were submitted for sequencing.

\section{Bioinformatic analysis}

The sequencing results were analysed in collaboration with biostatisticians from the Institute of Metabolic Science, University of Cambridge. Reads were mapped to the human genome using TopHat (v2.1.1 $)^{21}$ and Bowtie (v2.2.3) ${ }^{22}$. Transcripts were assembled, and the expression levels of genes were estimated using Cufflinks. Reads were normalised to counts per million (cpm) for all conditions, and differential gene expression was calculated using edgeR (3.26.8) $)^{23}$. Significant differential gene expression was defined as false discovery rate (FDR) $<0.05$. Differentially expressed genes were selected for pathway analysis using Metascape ${ }^{24}$.

\section{Real-time quantitative PCR (qPCR)}

RNA from healthy volunteer neutrophils was isolated using the RNeasy Mini kit (Qiagen, Germany) in accordance with the manufacturer's instructions and included an on-column DNase digestion step. cDNA libraries for qPCR analysis were generated using the High-Capacity cDNA Reverse Transcription Kit (Applied Biosystems) according to the manufacturer's instructions. qPCR reactions were prepared using SYBR green PCR Jumpstart Taq ReadyMix (Sigma-Aldrich) and ROX Reference Dye (Thermo Fisher Scientific), and these were added to the cDNA input in a total volume of $10 \mu \mathrm{L}$. Validated oligonucleotides to genes of interest were ordered from Quantitect (Qiagen) (Table 1) and added 1:10. The gene expression was quantified using a QuantStudio 6 Flex (Applied Biosystems). For each sample, triplicate amplifications were undertaken, and mean measurements were used for data analysis. Gene expression was normalised to the geometric mean of three reference genes Beta-2-Microglobulin (B2M), ribosomal protein L32 (RPL32) and receptor of activated protein

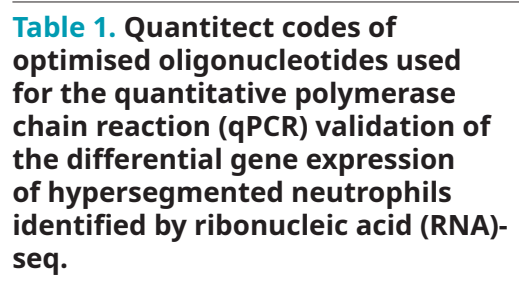

\begin{tabular}{|l|l|l|}
\hline Gene & GeneGlobe Id & Catalog No \\
\hline VCAN & QT00064064 & 249900 \\
\hline LTF & QT00096677 & 249900 \\
\hline PSMC4 & QT00035511 & 249900 \\
\hline PADI4 & QT00094689 & 249900 \\
\hline DUSP4 & QT00067018 & 249900 \\
\hline
\end{tabular}


C kinase 1 (RACK1), and the $\mathrm{N}$-fold differential expression was determined with the $2^{-\Delta \Delta \mathrm{CT}}$ method $^{25}$.

\section{Pharmacological inhibition of PADI4}

Neutrophils $\left(2.5 \times 10^{6}\right.$ cells $\left./ \mathrm{mL}\right)$ from healthy volunteers were isolated using dextran sedimentation and discontinuous plasma-Percoll gradients and resuspended in HBSS supplemented with $10 \%$ AS. Neutrophils were then incubated with $200 \mu \mathrm{M}$ of the PADI4-inhibitor Cl-amidine (Cayman Chemical) for $15 \mathrm{~min}$ alongside an untreated age-matched control (in triplicate) at $37{ }^{\circ} \mathrm{C}$ while shaking at $300 \mathrm{rpm}$. Following this incubation, three cytospins per triplicate condition were made. The slides were then fixed with methanol $(4 \mathrm{~min})$ and stained with Diffquick Red $(1 \mathrm{~min})$ then Blue $(3 \mathrm{~min})$ and three pictures per slide were taken using light microscopy (Olympus CX31RBSF) at 40x magnification.

\section{Statistical analysis}

Statistical analysis was undertaken using GraphPad Prism 7.0a software (GraphPad Software Inc.), but similar analyses could be undertaken using the open source platform R. Data were analysed with the non-parametric Friedman test and values of $\mathrm{p} \leq 0.05$ were considered to indicate statistical significance. Graphs present the median and range unless otherwise specified.

\section{Results}

\section{Captopril induces neutrophil hypersegmentation in} primary human neutrophils

To further our understanding of neutrophil hypersegmentation, we first had to overcome the lack of availability of hypersegmented neutrophils from patients. To do so, we established a robust model of neutrophil hypersegmentation in vitro by inducing hypersegmentation in healthy human neutrophils using the angiotensin converting enzyme inhibitor (ACEi), captopril. Captopril induced hypersegmentation in a study reporting the presence of hypersegmented neutrophils in the circulation of children treated with this $\mathrm{ACEi}^{26}$. This effect was further characterised by Shrestha et al. who described the concentration and time effect of captopril on neutrophil lobularity along with the induction of an antitumor phenotype ${ }^{13,27}$. We replicated these experimental findings and identified the optimal concentrations of captopril needed to induce hypersegmentation.

Human neutrophils from three healthy volunteers were stimulated with increasing concentrations of the ACEi captopril ranging from 0 to $1000 \mu \mathrm{M}$ for 3 hours. We observed a dose-dependent increase in hypersegmentation with captopril (Figure 1A). Having determined that $300 \mu \mathrm{M}$ was the optimum concentration of captopril, we then explored the time-dependent effects of ACEi on hypersegmentation. Neutrophils were incubated with $300 \mu \mathrm{M}$ captopril for 0 to 6 hours, with hypersegmentation peaking at 2 hours, reaching 24.4\% (Figure 1D-F).

After establishing this model of neutrophil hypersegmentation, we sought to identify genes and pathways involved in this dynamic chromatin rearrangement.
Laser capture microdissection (LCM) allows the isolation of neutrophils according to their morphology

Until now, the inability to separate an enriched population of hypersegmented neutrophils has limited our understanding of this nuclear phenotype. We adapted the laser capture microdissection (LCM) technique to observe and isolate a population of captopril-induced hypersegmented neutrophils from a morphologically heterogenous neutrophil sample in order to characterise the genomic context of hypersegmentation.

Figure 2 illustrates our final optimised LCM workflow. Figure 3 shows the isolation of a normally segmented control neutrophil using LCM: a gate is manually drawn around the selected neutrophil (Figure 3A), the laser cuts following the defined borders (Figure 3B, C), and the PEN-membrane with the neutrophil falls in the lid of a collector Eppendorf (Figure 3D).

\section{Next generation sequencing of total RNA from laser} capture microdissected neutrophils

Following the optimisation of each step of the sample preparation workflow, we conducted RNA-seq to assess whether hypersegmentation in neutrophils was associated with transcriptomic changes. Four populations of neutrophils were manually isolated using LCM: normally segmented baseline neutrophils, normally segmented $2 \mathrm{~h}$ age-matched neutrophils, normally segmented $2 \mathrm{~h}$ captopril-treated neutrophils, and captopril-treated hypersegmented neutrophils.

The average library length of the submitted samples was 354 bp and ranged from 296 to $438 \mathrm{bp}$, with an average molarity of $4690 \mathrm{pM} / \mathrm{L}$. Bioinformatic quality control analysis did not report any consequent bacterial contamination or presence of forward strands. A minimum mappability threshold was established in order to select only high-quality samples in the analysis and to avoid introducing biases. Four samples with a mappability below $40 \%$ were not included in the analysis. Baseline samples had an average of 36 million reads, and their percentage of uniquely mapped reads to the human genome ranged between $64 \%$ and $80 \%$. The age-matched neutrophils had an average of 28 million reads, with uniquely mapped reads ranging between $63 \%$ and $83 \%$; the normally segmented captopril treated condition also had an average of 28 million reads with a 59-79\% mappability. Hypersegmented neutrophils had 31 million reads on average with $72-82 \%$ uniquely mapped reads.

Transcriptomic signature of hypersegmented neutrophils reveals significantly differentially expressed genes as well as novel modulated pathways

Differential gene expression and pathway enrichment analysis revealed that neutrophil hypersegmentation was associated with marked transcriptomic changes (Accession number GSE173553; https://identifiers.org/geo:GSE173553). In total, five genes significantly regulated in hypersegmented neutrophils, with several pathways differentially modulated; this provided further insights into the mechanisms associated with this chromatin rearrangement (Figure 4A; Table 2). 


\section{A}

$0 \mu \mathrm{M}$

$300 \mu \mathrm{M}$

$1000 \mu \mathrm{M}$

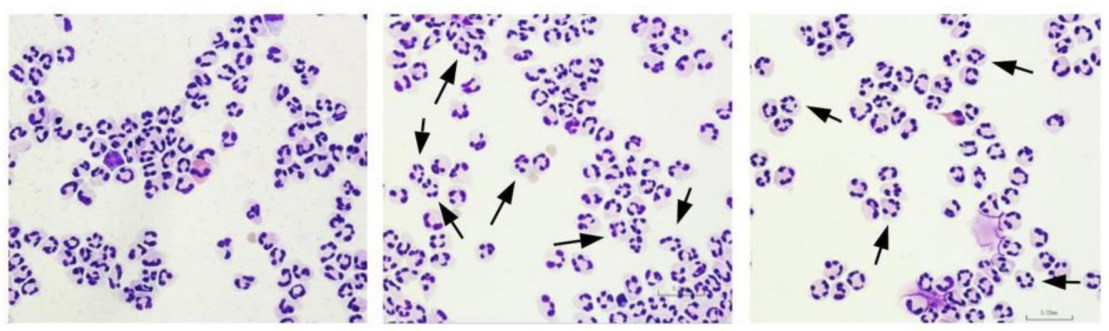

B

$\mathrm{Oh}$

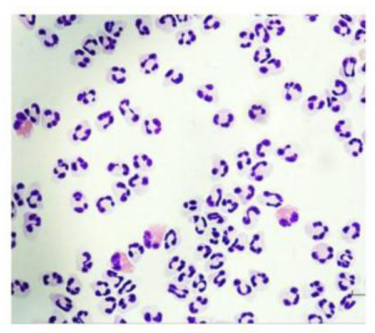

C
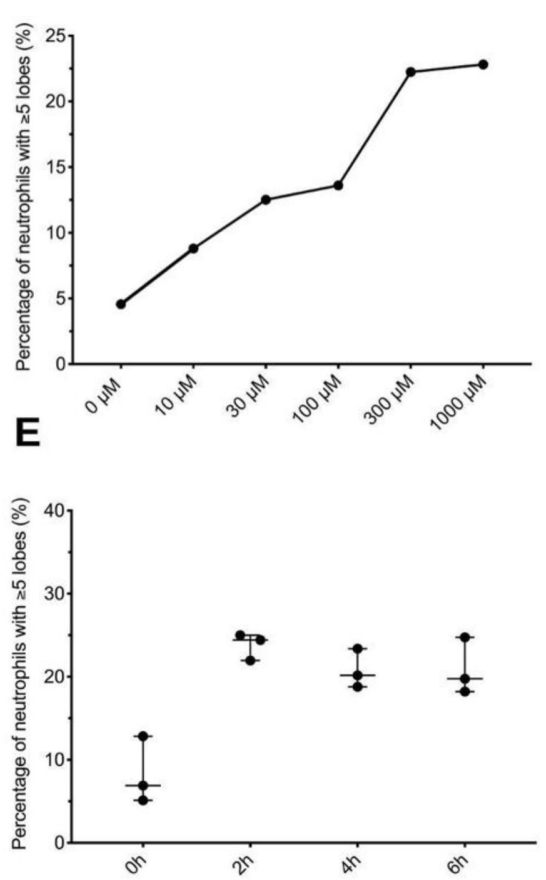

$2 \mathrm{~h}$

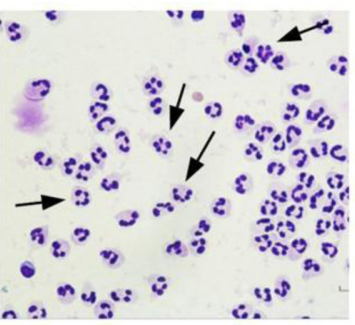

$4 \mathrm{~h}$

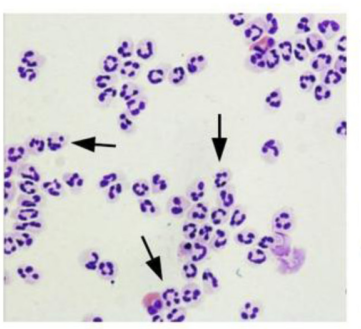

$6 \mathrm{~h}$

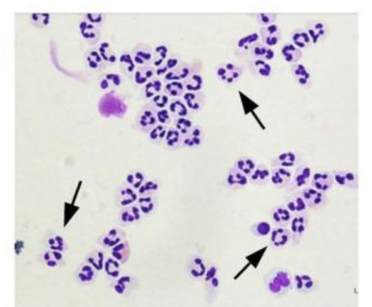

D
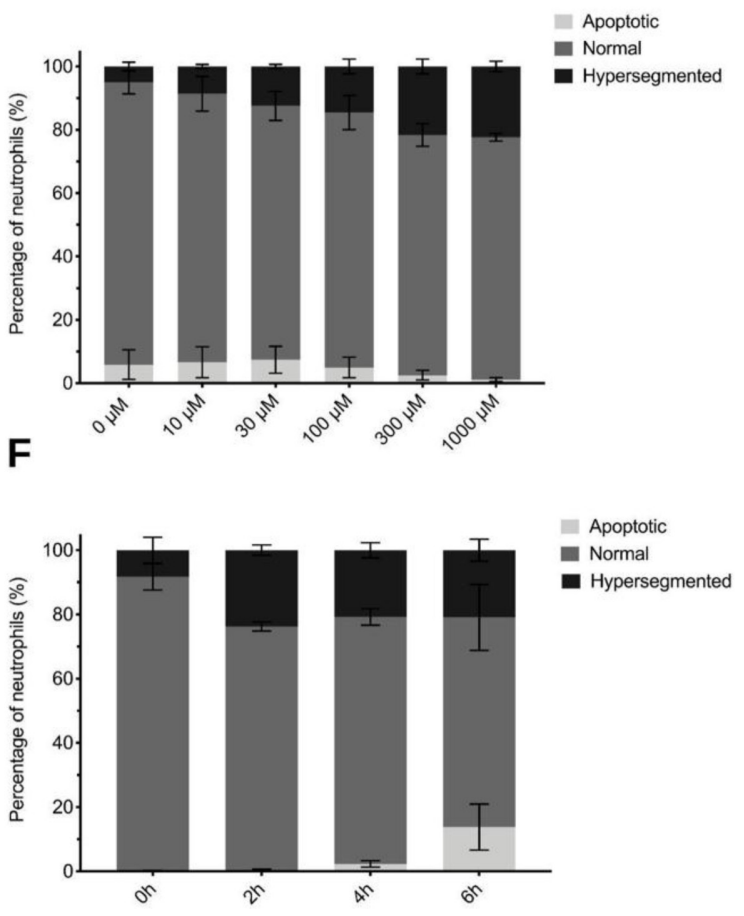

Figure 1. The angiotensin converting enzyme (ACE)-inhibitor captopril induces a concentration-dependent increase in neutrophil nuclear hypersegmentation. (A-C) Healthy peripheral blood neutrophils $\left(2.5 \times 10^{6} \mathrm{cell} / \mathrm{s} / \mathrm{mL}\right)$ were cultured in Hank's Balanced Salt Solution (HBSS) with $10 \%$ autologous serum. Neutrophils were treated with increasing concentrations of captopril $(0 \mu \mathrm{M}$ to $1000 \mu \mathrm{M})$ in triplicate, for 3 hours at $37^{\circ} \mathrm{C}$ shaking at $300 \mathrm{rpm}$. Cytospins were prepared for each condition, slides were air-dried then fixed with methanol for 4 min, stained with Diff Quick Red for 1 min and Diff Quick Blue for 3 min. Neutrophil morphology was assessed in a blinded manner by light microscopy, and each neutrophil was categorised as apoptotic, normally lobulated (2 to 4 lobes) or hypersegmented (5 lobes or more). There is an increase in the percentage of hypersegmented neutrophils ( $\mathrm{A}$, black arrows) with increasing captopril concentrations (B, C) $(p \leq 0.05$ when analysed with the non-parametric Friedman test $(n=3))$. (D-F) Neutrophils were treated with $300 \mu M$ captopril for 0 to 6 hours, in triplicate, at $37^{\circ} \mathrm{C}$, shaking at $300 \mathrm{rpm}$. Morphologic analysis was undertaken on cytospins preparations in a similar blinded manner to above. Hypersegmentation was quantified (A, black arrows) and peaked following a 2-hour incubation reaching 24.4.\% $(\mathbf{B}, \mathbf{C})(n=3)$. No modifications were made to the microscopy images presented. 


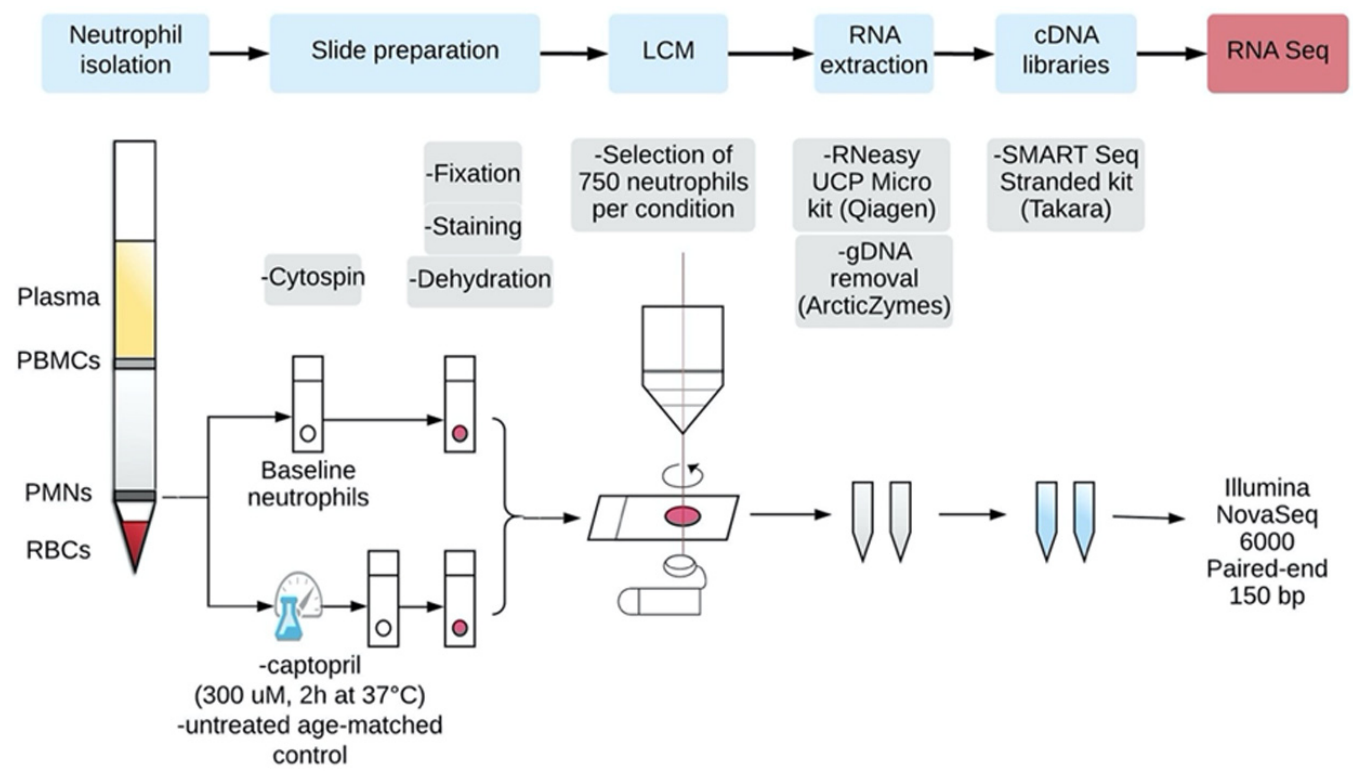

Figure 2. Workflow of laser capture microdissection transcriptomic analysis of neutrophils. Cytospins of freshly isolated healthy peripheral blood neutrophils were either made immediately using polyethylene naphtalate (PEN)-membrane microscope slides (baseline) or cells were treated for two hours at $37^{\circ} \mathrm{C}$ in the presence and absence of captopril prior to cytospins being made. Slides were then fixed, stained and dehydrated following a protocol optimised to preserve ribonucleic acid (RNA) integrity, before laser capture microdissection was used to select 1500 neutrophils for each condition, according to their morphology. RNA was extracted using spin column, and an additional DNase incubation step was undertaken prior to CDNA library preparation. Paired-end 150 bp sequencing was undertaken using an Illumina NovaSeq 6000 S1 Flow Cell. The transcriptome of hypersegmented neutrophils was compared to that of captopril-treated non-hypersegmented neutrophils.
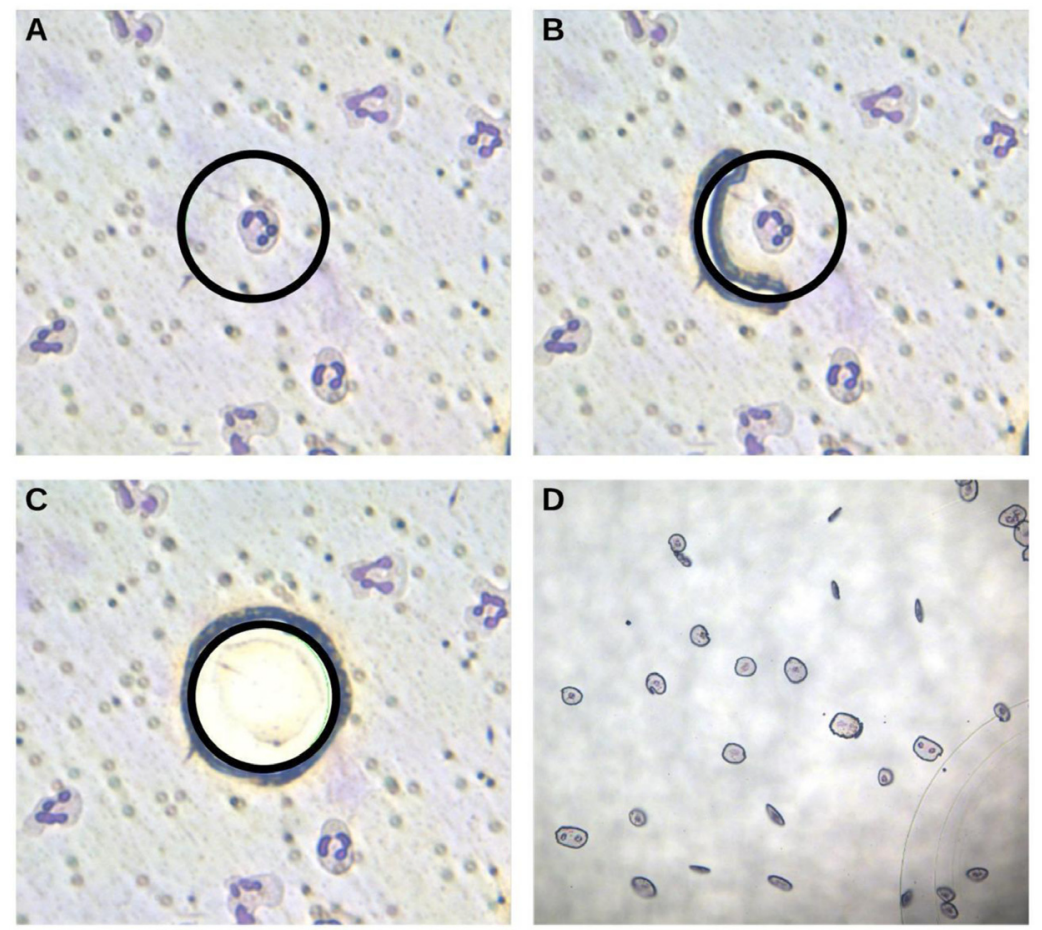

Figure 3. Laser capture microdissection allows the isolation of neutrophils according to their morphology. (A) A gate is drawn around a selected neutrophil. (B-C) The laser cuts the polyethylene naphtalate (PEN)-membrane allowing the dissected area to fall into a collection tube. (D) The micro-dissected neutrophils are visible in the collection tube. No modifications were made to the microscopy images presented. 


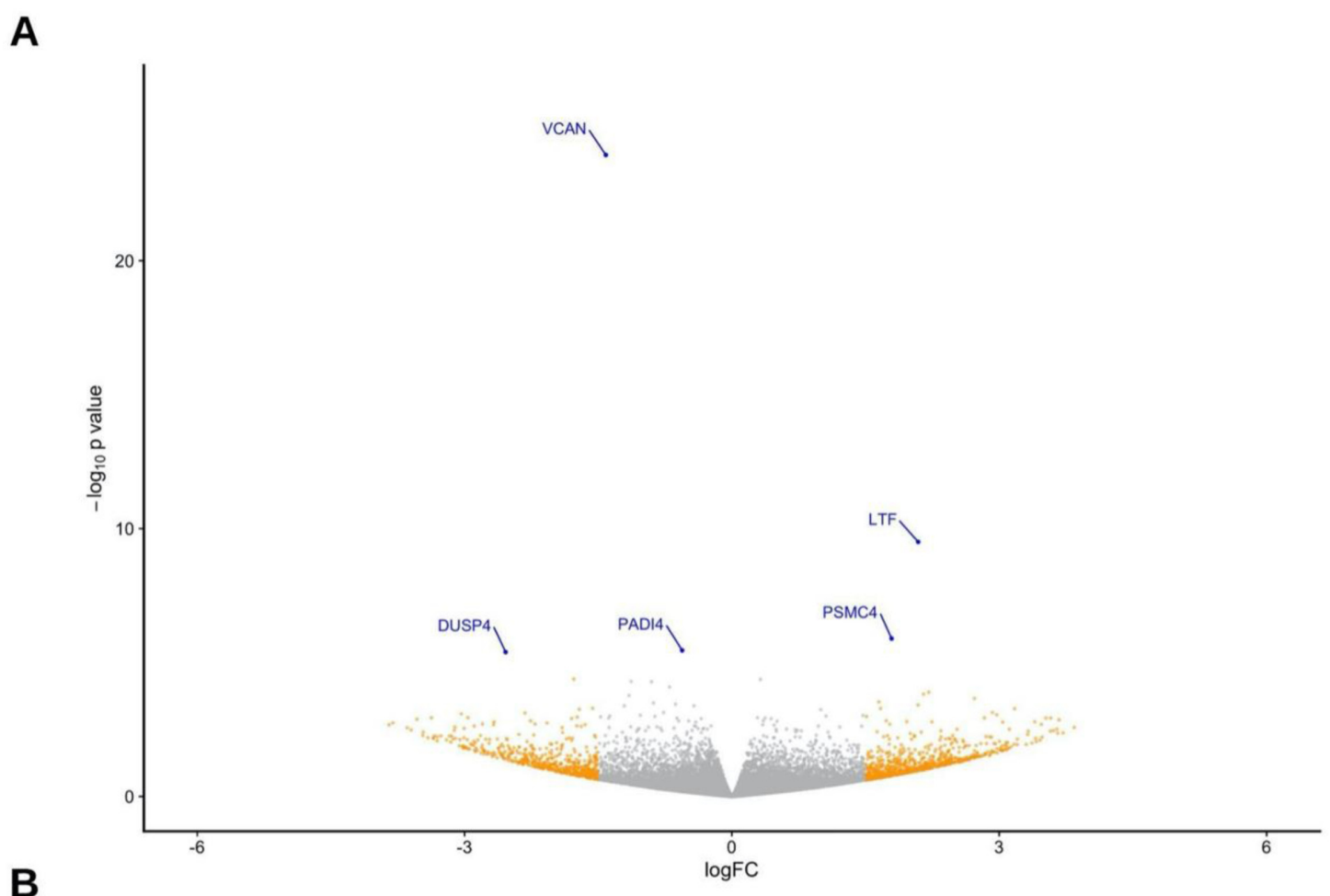

B

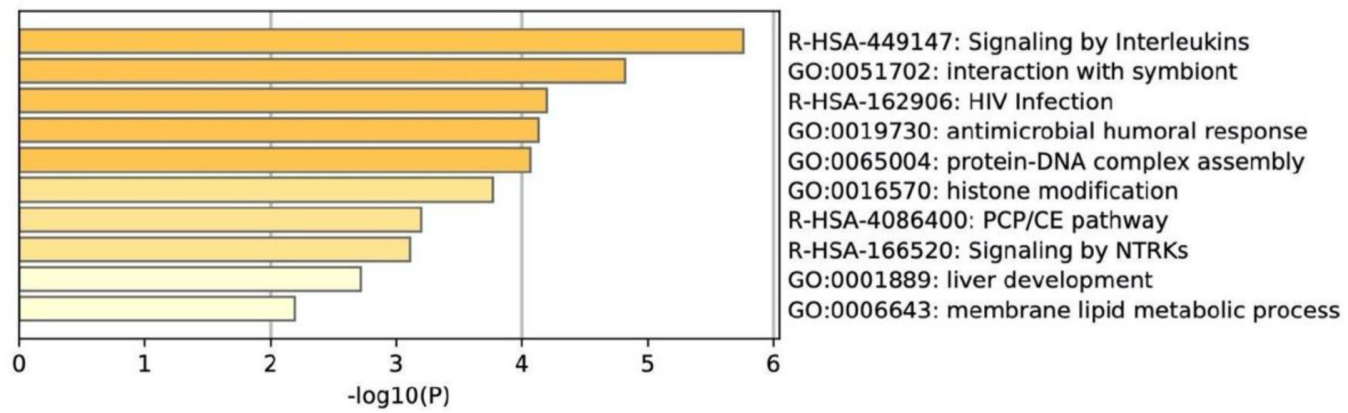

Figure 4. Hypersegmented neutrophils have differentially expressed genes and pathways compared to captopril-treated nonhypersegmented neutrophils. (A) The ribonucleic acid (RNA)-seq analysis revealed that five transcripts were differentially expressed in hypersegmented neutrophils (false discovery rate (FDR) $\leq 0.05$ ). The volcano plot shows the differentially expressed genes with the significant genes labelled in blue, and the ones with a fold change $\geq 1.5$ in orange for scale. (B) Pathway enrichment analysis was undertaken using Metascape based on differentially expressed genes, highlighting the pathways modulated in hypersegmentation like signalling by interleukins, protein-DNA complex assembly and histone modification.

The protein coding gene versican (VCAN) was downregulated in hypersegmented neutrophils with a log fold change of -1.4 and an FDR of $8.7 \times 10^{-21}$. VCAN is known to be associated with cellular processes such as protein-DNA complex assembly, cell proliferation and adhesion, and post-translational protein phosphorylation ${ }^{24,28,29}$. It has been extensively studied for its role in inflammation and in lungs disorders like chronic obstructive pulmonary disease (COPD) or asthma $\mathrm{a}^{30,31}$.

Another significantly downregulated gene, PADI4, has also been extensively linked to post-translational modification in neutrophils, and more precisely to histone citrullination. PADI4 is known for its role in chromatin decondensation in neutrophils and its role in neutrophil extracellular trap (NET) formation ${ }^{32,33}$. Our RNA-seq dataset revealed a small but significant downregulation of PADI4 in hypersegmented neutrophils, suggesting the potential involvement of histone citrullination and chromatin condensation in the hypersegmentation process.

Lactotransferrin $(L T F)$ and proteasome 26S Subunit, ATPase 4 (PSMC4) genes were significantly upregulated with $\log$ fold changes of 2.1 and 1.8 respectively, and dual specificity phosphatase 4 (DUSP4) was downregulated.

Other potentially relevant genes appeared to be differentially expressed in our dataset without reaching statistical significance, 
Table 2. 50 genes most differentially expressed in hypersegmented neutrophils, ordered by false discovery rate (FDR).

\begin{tabular}{|c|c|c|c|c|}
\hline Gene ID & $\log F C$ & $\log$ CPM & P Value & FDR \\
\hline VCAN & -1.4151 & 7.3287 & 0.0000 & 0.0000 \\
\hline LTF & 2.0905 & 4.5718 & 0.0000 & 0.0000 \\
\hline PSMC4 & 1.7925 & 3.8879 & 0.0000 & 0.0033 \\
\hline PADI4 & -0.5583 & 7.3147 & 0.0000 & 0.0077 \\
\hline DUSP4 & -2.5397 & 3.1804 & 0.0000 & 0.0078 \\
\hline TNS1 & -1.7744 & 3.6529 & 0.0000 & 0.0659 \\
\hline HIVEP2 & 0.3217 & 9.1743 & 0.0000 & 0.0659 \\
\hline CD300E & -1.1306 & 5.7591 & 0.0001 & 0.0672 \\
\hline DDX42 & -0.9023 & 4.9935 & 0.0001 & 0.0672 \\
\hline PAXBP1 & -0.7003 & 7.1133 & 0.0001 & 0.0963 \\
\hline PGAP1 & 2.2096 & 2.9492 & 0.0001 & 0.1419 \\
\hline SUMF1 & 2.1503 & 2.9332 & 0.0002 & 0.1550 \\
\hline CXCL2 & -1.1536 & 4.3920 & 0.0002 & 0.1626 \\
\hline LOC102723897 & 2.7223 & 2.4229 & 0.0002 & 0.1986 \\
\hline CDK7 & 1.6503 & 3.3478 & 0.0003 & 0.2540 \\
\hline CDC34 & -0.8803 & 4.9062 & 0.0003 & 0.2647 \\
\hline SLC12A9 & -0.6326 & 5.8967 & 0.0004 & 0.2772 \\
\hline C19orf53 & 2.0897 & 2.8261 & 0.0004 & 0.2772 \\
\hline METRNL & -0.4251 & 7.0392 & 0.0004 & 0.2772 \\
\hline AIP & -1.2074 & 3.8774 & 0.0004 & 0.2772 \\
\hline TUBB1 & -1.5626 & 3.5285 & 0.0005 & 0.3136 \\
\hline LCN2 & 1.6680 & 3.5509 & 0.0005 & 0.3136 \\
\hline AUTS2 & 3.1728 & 2.0110 & 0.0005 & 0.3136 \\
\hline PKD2 & -1.7118 & 2.9855 & 0.0006 & 0.3142 \\
\hline STOM & 0.9988 & 4.4799 & 0.0006 & 0.3142 \\
\hline TGFBI & -0.7666 & 5.8627 & 0.0007 & 0.3631 \\
\hline FAM213B & 2.9241 & 2.0674 & 0.0007 & 0.3631 \\
\hline LLGL2 & -2.3218 & 2.4330 & 0.0008 & 0.3631 \\
\hline COMMD10 & -3.0367 & 1.9960 & 0.0008 & 0.3631 \\
\hline IL21R & 2.9734 & 2.0758 & 0.0009 & 0.3631 \\
\hline RNGTT & -1.0281 & 4.1108 & 0.0009 & 0.3631 \\
\hline OSMR & 1.4713 & 3.4561 & 0.0010 & 0.3631 \\
\hline WNT4 & -1.3698 & 3.5114 & 0.0010 & 0.3631 \\
\hline OXR1 & 1.0551 & 4.0716 & 0.0010 & 0.3631 \\
\hline RP11-692N5.1 & -0.8644 & 4.8713 & 0.0010 & 0.3631 \\
\hline FYN & 1.5121 & 3.3973 & 0.0010 & 0.3631 \\
\hline
\end{tabular}

\begin{tabular}{|l|l|l|l|l|}
\hline Gene ID & log FC & log CPM & P Value & FDR \\
\hline DDB1 & -1.4732 & 3.3701 & 0.0011 & 0.3631 \\
\hline INTS6-AS1 & -1.7352 & 2.8438 & 0.0011 & 0.3631 \\
\hline TALD01 & 0.2873 & 8.9019 & 0.0011 & 0.3631 \\
\hline ADA & -2.9625 & 1.9112 & 0.0011 & 0.3631 \\
\hline HIST1H2BE & -3.3716 & 1.7402 & 0.0012 & 0.3631 \\
\hline ANXA4 & 2.8339 & 2.1095 & 0.0012 & 0.3631 \\
\hline VAPA & 0.3719 & 7.2958 & 0.0012 & 0.3631 \\
\hline MIER2 & 3.5781 & 1.7505 & 0.0012 & 0.3631 \\
\hline CCDC43 & 3.5252 & 1.7614 & 0.0012 & 0.3631 \\
\hline ING5 & -1.3851 & 3.3167 & 0.0012 & 0.3631 \\
\hline AP2A1 & -0.6175 & 5.5657 & 0.0012 & 0.3631 \\
\hline WDR5B & -1.8002 & 2.7340 & 0.0012 & 0.3631 \\
\hline CELF1 & 0.4404 & 6.7763 & 0.0012 & 0.3631 \\
\hline TTN & -0.3440 & 7.4947 & 0.0012 & 0.3631 \\
\hline
\end{tabular}

and it is possible an enlarged experiment would have increased statistical power (Table 2). For example, the WAS protein family homolog 9 was found to be upregulated by a $\log$ fold change of 2.7 and a p-value of $2 \times 10^{-4}$ but an FDR of 0.19 . This gene is involved in the process of Arp2/3 complex-mediated actin nucleation, the process by which actin monomers combine to form new branches on existing actin filaments ${ }^{34}$.

To further understand this subset of neutrophils, we conducted a pathway enrichment analysis on the differentially expressed genes. Unsurprisingly, histone modification was one of the main enriched pathways, alongside protein-DNA complex assembly, signalling by interleukins and antimicrobial humoral response (Figure 4B).

\section{Validation of expression of genes involved in hypersegmentation}

We confirmed the changes in gene expression observed in the RNA-seq dataset using qPCR. A bulk pool of captopril-treated neutrophils from four additional healthy volunteers was compared to age-matched neutrophils, instead of morphology-selected cells. VCAN, LTF, PSMC4, PADI4 and DUSP4 expressions were quantified, and all but one (DUSP4) were found to be differentially expressed in the same direction as in the RNA-seq dataset, thereby confirming our findings (Figure 5). Interestingly, DUSP4 was also the only gene for which the primers had a $67 \%$ efficiency; this is far below the established accepted threshold of $90 \%$, and this may explain the discrepancy.

\section{Validation of the transcriptomic dataset in primary human neutrophils by pharmacological inhibition of PADI4}

We sought to further explore the role of PADI4 in the process of hypersegmentation due to its well-documented roles in 
VCAN

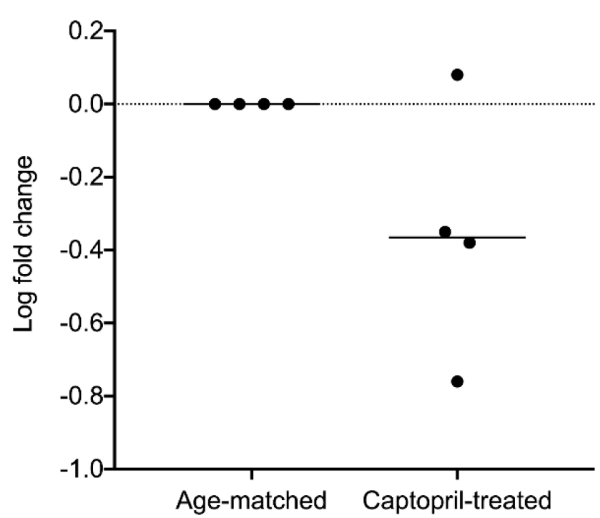

PSMC4

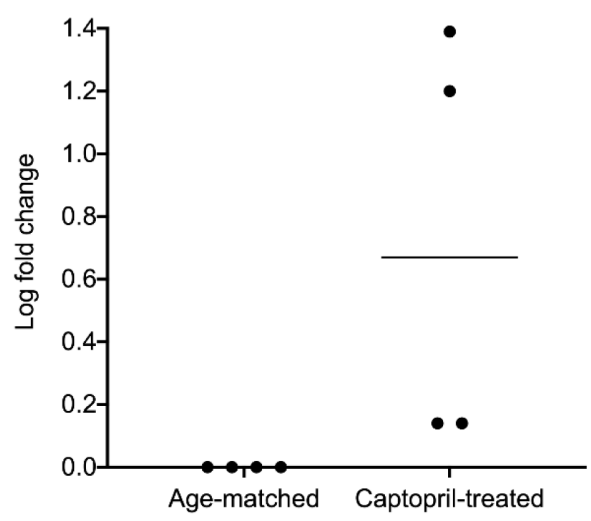

LTF

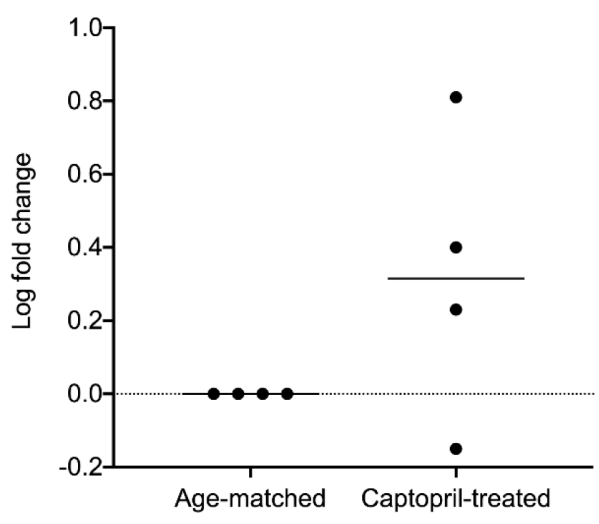

PADI4

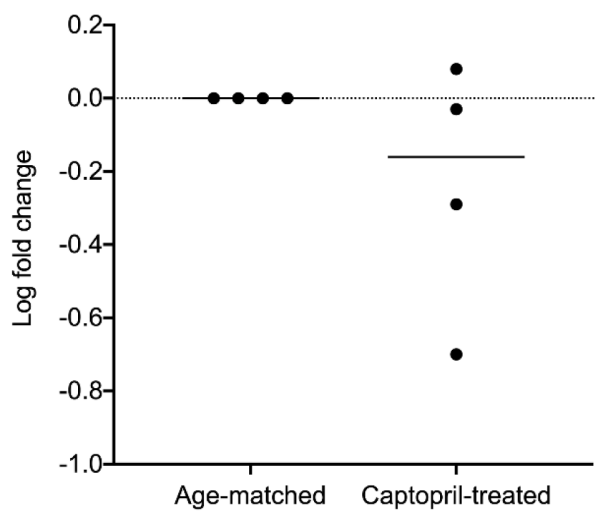

DUSP4

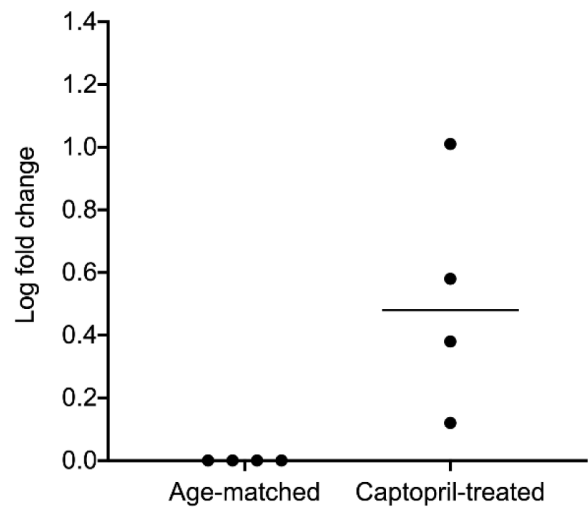

Figure 5. Validation of RNA-seq differential gene expression analysis by q-PCR in hypersegmented neutrophils normalised to age-matched neutrophils. The ribonucleic acid (RNA) of captopril-treated neutrophils and age-matched neutrophils from four additional healthy volunteers was isolated and the levels of the five significantly differentially expressed genes were quantified by quantitative polymerase chain reaction (q-PCR). Four out of the five genes were found to be up- or down-regulated in the same direction as in the RNA-seq dataset when normalised to the age-matched controls. DUSP4 was found to be upregulated instead of downregulated in the RNA-seq but the primers efficiency was also found to be low for this particular gene. No modifications were made to the microscopy images presented. 
chromatin packing and NET formation ${ }^{32,33,35,36}$. Primary human neutrophils were treated either with the PADI4 pharmacological inhibitor $\mathrm{Cl}$-amidine, or with captopril alongside baseline and age-matched untreated control. Morphologic analysis revealed that $\mathrm{Cl}$-amidine treatment led to neutrophil hypersegmentation. The proportion of cells with five or more lobes was similar to those obtained with captopril (around 20\%), validating the RNA-seq findings (Figure 6A, B). Additionally, the lobe distributions highlighted the striking similarities in the right shifts caused by captopril and $\mathrm{Cl}$-amidine thereby validating the involvement of PADI4 downregulation in captopril-induced neutrophil hypersegmentation (Figure 6C).

\section{Discussion}

This study successfully established the first transcriptomic analysis of neutrophil hypersegmentation. Although neutrophil nuclear hypersegmentation, present in various disease states and in response to diverse stimuli, has frequently been described $^{12-14,27,37}$, very little is known about the mechanism or pathways involved. We established a model of hypersegmentation

A Baseline Age-matched Captopril Cl-amidine

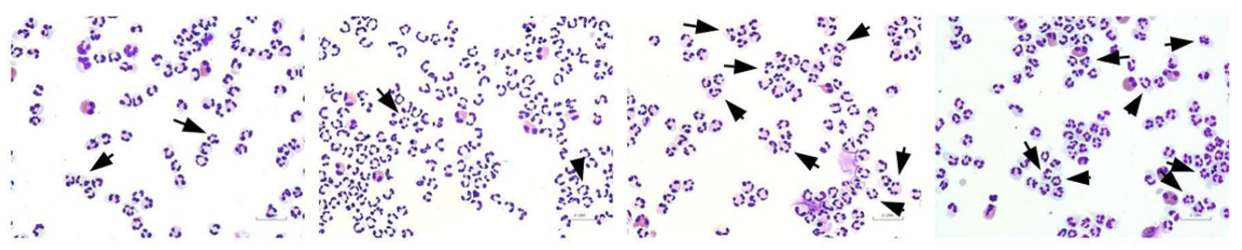

B
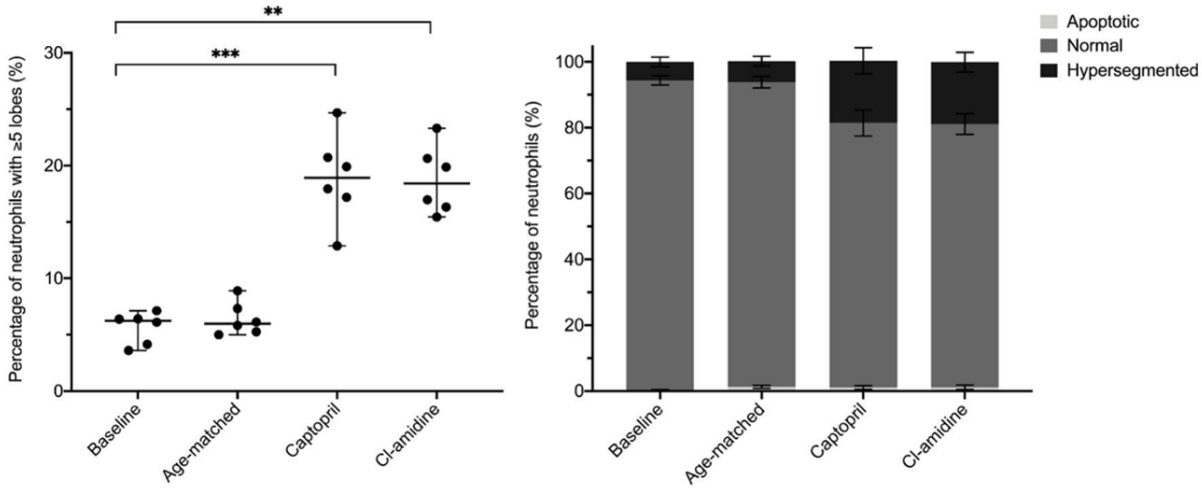

C

Age-matched Captopril
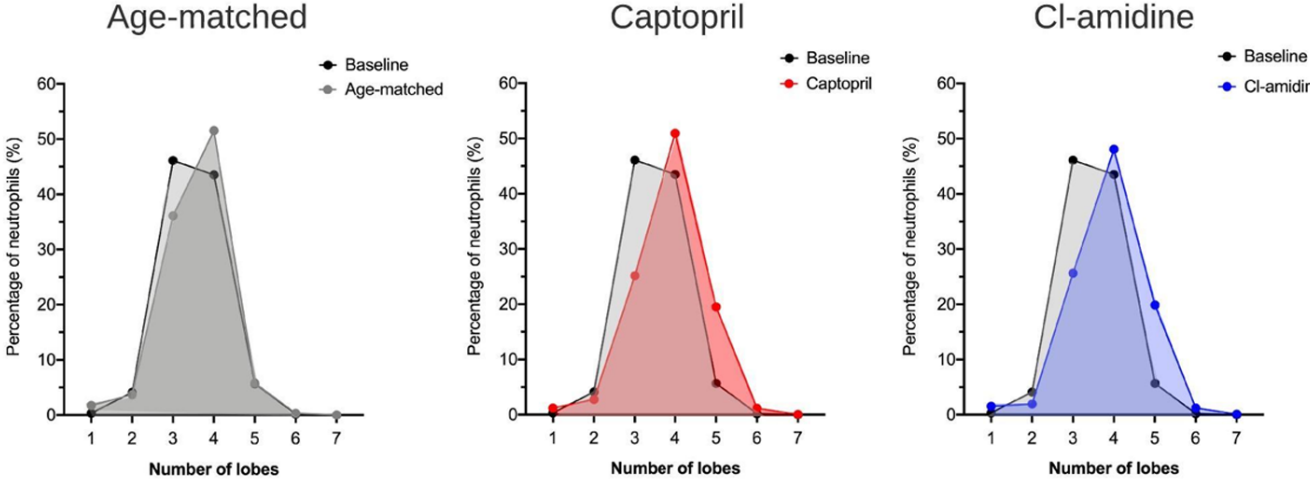

Figure 6. Treating neutrophils with $\mathrm{Cl}$-amidine confirms the role of PADI4 on hypersegmentation. (A, B) Healthy peripheral blood neutrophils $\left(2.5 \times 10^{6}\right.$ cells $\left./ \mathrm{mL}\right)$ were cultured in Hank's Balanced Salt Solution (HBSS) with $10 \%$ autologous serum. Neutrophils were either centrifuged directly on cytospins for the baseline condition or incubated in a thermomixer shaking gently at 300 rpm, at $37^{\circ} \mathrm{C}$, in triplicate, with $\mathrm{Cl}$-amidine $(15 \mathrm{~min}, 200 \mu \mathrm{M})$ or captopril $(2 \mathrm{~h}, 300 \mu \mathrm{M})$. Cytospins were prepared for each condition, slides were air-dried then fixed with methanol for 4 min, stained with Diff Quick Red for 1 min and Diff Quick Blue for 3 min. Neutrophil morphology was assessed in a blinded manner by light microscopy, and each neutrophil was categorised as apoptotic, normally lobulated (2 to 4 lobes) or hypersegmented (5 lobes or more). Neutrophils treated with Cl-amidine or captopril were hypersegmented (A, black arrows) and exhibited a higher percentage of cells with five lobes compared to an untreated control (B) $(p \leq 0.05$ when analysed with the non-parametric Friedman test $(n=6))$. (C) The lobe distributions obtained in response to each of the treatments, with each circle representing the median of the three biological replicates, highlight the similarities in the right shift caused by captopril and Cl-amidine. 
in primary human neutrophils using the ACEi captopril and undertook RNA sequencing of an enriched population of hypersegmented neutrophils, selected according to their nuclear morphology using LCM.

We identified five differentially expressed transcripts in microdissected hypersegmented neutrophils. Our dataset highlights that neutrophil hypersegmentation is seemingly associated with the differential expression of multiple genes - PADI4, VCAN, LTF, PSMC4, and DUSP4.

The involvement of PADI4 in the hypersegmentation process, validated by both qPCR and the use of the small molecule inhibitor $\mathrm{Cl}$-amidine, provides a novel mechanism for this chromatin rearrangement. PADI4 is one of the five isozymes of the peptidyl-arginine deiminase enzymes involved in various physiological processes from myelin sheath maintenance to gene expression regulation ${ }^{38}$. PADI4 catalyses post-translational protein citrullination, a process by which the amino acid arginine is converted into citrulline ${ }^{39}$. Histone citrullination is crucial in neutrophil NET formation and extrusion as it leads to chromatin decondensation and the formation of DNA structures that characterise these extracellular traps ${ }^{40}$.

Due to PADI4's role in chromatin decondensation in NET formation and its downregulation in our transcriptomic analysis, we hypothesised that this protein may play an important role in the chromatin rearrangement observed in hypersegmentation. PADI4 downregulation may be associated with increased chromatin condensation and potentially more lobe formation in an opposite fashion to that in NET formation. In agreement with this idea, a study by Wang et al., demonstrated that PADI4 activation in the neutrophil-like cells, human promyelocytic leukaemia cells (HL-60s), was associated with the loss of their mulitlobar morphology ${ }^{40}$. This finding along with our observations further supports the association between a downregulation of PADI4 and increased lobularity.

The differential expression of $V C A N$ in our dataset adds another layer of complexity to this already poorly characterised gene. From its contribution to extracellular matrix accumulation and leukocyte infiltration in inflammatory respiratory diseases such as asthma ${ }^{30}$ to its upregulation in skin tumorigenesis ${ }^{41}$, cutaneous melanoma ${ }^{31}$, and prostate cancer $^{42}$, the role of VCAN is broad. Initially believed to be mostly involved in extracellular signalling such as cell adhesion, proliferation, or migration, it is now thought to be additionally involved in intracellular processes such as cell mobility, growth and differentiation ${ }^{43}$. The observed downregulation of VCAN mRNA in our transcriptomic analysis is hard to interpret without further validation as its role in neutrophils has yet to be characterised.

Although lactotransferrin is one of the most abundant proteins in mature neutrophils and is a major constituent of the neutrophil antimicrobial response, literature has shown that its mRNA levels decrease after granulocyte differentiation and are low in mature circulating blood neutrophils ${ }^{44,45}$. The upregulation observed in our dataset may therefore be representative of a differential maturation status. Alternatively, this increase could be a marker of an increase in lactotransferrin and antimicrobial response initiated at the transcriptome level and hence a sign of a functional difference since lactotransferrin stimulates the TLR4 signalling pathway leading to NK-kappa-B activation and subsequent pro-inflammatory cytokine production ${ }^{43}$.

PSMC4 gene, traditionally known to be part of the $26 \mathrm{~S}$ proteasome and involved in the maintenance of protein homeostasis by removing misfolded or damaged proteins, has more recently proven itself to be involved in many different modulated pathways, including cell extension formation in fibroblast enabling matrix remodelling ${ }^{46}$ and cell proliferation and tumorigenesis ${ }^{47}$. Assuming that hypersegmentation is associated with a shift in the cellular machinery of neutrophils leading to certain proteins becoming redundant or damaged, and based on PSMC4's function, we can speculate that its upregulation may be involved in the removal of misfolded, damaged, or no longer used proteins, but this has not yet been demonstrated.

Finally, the importance of DUSP4 in neutrophil hypersegmentation is still to be determined. Having not been validated by qPCR analysis but with the confounding factor of low primer efficiency, it is unclear whether DUSP4 downregulation plays a role in this process or if it is an experimental artefact. The dual-specificity phosphatase (DUSP) gene family is well characterised for its involvement in immunity and infection due to its role in reversible phosphorylation and signal transduction ${ }^{48}$. Despite many members of the DUSP family having been shown to be present in neutrophils ${ }^{49}$, the presence of DUSP4 and its role in neutrophil function remain poorly characterised.

Laser capture microscopy (LCM) is an ideal tool for the collection of cells or tissue based on their morphology and may easily be coupled with increasingly sensitive transcriptomic analyses that require only small amounts of input. Despite its many advantages, LCM remains an expensive and time-constraining technique where every step must be rapidly undertaken in order to preserve RNA integrity. Additionally, the isolation of single cells according to their morphology is a laborious process. Ideally, future advances will lead to automatic image analysis based on user-defined selection criteria for more rapid selection whilst retaining the precision of the overall method.

The adaptation of LCM to the isolation of neutrophils according to their morphology will allow further research on neutrophil morphologic phenotype. Our study represents, the first transcriptomic dataset of microdissected neutrophils. Analyses of this dataset revealed that transcriptomic analysis using RNA-seq can be achieved in neutrophils despite the challenges associated with their low levels of RNA. Additionally, our data also constitutes the first RNA-seq analysis of both hypersegmented and ex vivo aged human neutrophils, providing insights into both the mechanisms of hypersegmentation and highlighting that neutrophils are transcriptionally active 
cells undergoing marked transcriptional changes in as little as two hours.

\section{Data availability}

NCBI Gene Expression Omnibus: RNAseq data. Accession number GSE173553; https://identifiers.org/geo:GSE173553.

\section{Acknowledgements}

We would like to acknowledge the assistance of Sherine Awad and Davide Chiarugi from the Institute of Metabolic Science, University of Cambridge, who provided help with the initial bioinformatic analysis of the RNAseq dataset.
1. Summers C, Rankin SM, Condliffe AM, et al.: Neutrophil Kinetics in Health and Disease. Trends Immunol. 2010; 31(8): 318-24.

PubMed Abstract | Publisher Full Text | Free Full Text

2. Bain BJ: Blood Cells: A Practical Guide. Fourth Edition. Wiley; 2008; 92. Publisher Full Text

3. Rowat AC, Jaalouk DE, Zwerger $\mathrm{M}$, et al: Nuclear Envelope Composition Determines the Ability of Neutrophil-Type Cells to Passage through Micron-Scale Constrictions. J Biol Chem. 2013; 288(12): 8610-18. PubMed Abstract | Publisher Full Text | Free Full Text

4. Dale DC, Boxer L, Liles WC: The phagocytes: neutrophils and monocytes. Blood. 2008; 112(4): 935-945.

PubMed Abstract | Publisher Full Text

5. Hellebrekers P, Vrisekoop N, Koenderman L: Neutrophil Phenotypes in Health and Disease. Eur J Clin Invest. 2018; 48 Suppl 2(Suppl Suppl 2): e12943. PubMed Abstract | Publisher Full Text | Free Full Text

6. Juss JK, House D, Amour A, et al.: Acute Respiratory Distress Syndrome Neutrophils Have a Distinct Phenotype and Are Resistant to Phosphoinositide 3-Kinase Inhibition. Am J Respir Crit Care Med. 2016; 194(8): 961-73.

PubMed Abstract | Publisher Full Text | Free Full Text

7. Carvalho LO, Nascimento Aquino E, Dias Neves AC, et al.: The Neutrophil Nucleus and Its Role in Neutrophilic Function. J Cell Biochem. 2015; 116(9): 1831-36.

PubMed Abstract | Publisher Full Text

8. Manley HR, Keightley MC, Lieschke G]: The Neutrophil Nucleus: An Important Influence on Neutrophil Migration and Function. Front Immunol. 2018; 9: 2867.

PubMed Abstract | Publisher Full Text | Free Full Text

9. Hoffmann K, Sperling K, Olins AL, et al.: The Granulocyte Nucleus and Lamin B Receptor: Avoiding the Ovoid. Chromosoma. 2007; 116(3): 227-35. PubMed Abstract | Publisher Full Text

10. van Grinsven E, Textor J, Hustin LSP, et al.: Immature Neutrophils Released in Acute Inflammation Exhibit Efficient Migration despite Incomplete Segmentation of the Nucleus. J Immunol. 2019; 202(1): 207-217. PubMed Abstract | Publisher Full Text

11. Fingerhut $\mathrm{L}$, Dolz $\mathrm{G}$, de Buhr $\mathrm{N}$ : What Is the Evolutionary Fingerprint in Neutrophil Granulocytes? Int J Mol Sci. 2020; 21(12): 4523 PubMed Abstract | Publisher Full Text | Free Full Text

12. Whitmore LC, Weems MN, Allen LH: Cutting Edge: Helicobacter Pylori Induces Nuclear Hypersegmentation and Subtype Differentiation of Human Neutrophils In Vitro. J Immunol. 2017; 198(5): 1793-97. PubMed Abstract | Publisher Full Text | Free Full Text

13. Fridlender ZG, Sun J, Kim S, et al.: Polarization of Tumor-Associated Neutrophil Phenotype by TGF-Beta: "N1" versus "N2" TAN. Cancer Cell. 2009; 16(3): 183-94.

PubMed Abstract | Publisher Full Text | Free Full Text

14. Lokwani R, Wark PAB, Baines $\mathrm{KJ}$, et al.: Hypersegmented airway neutrophils and its association with reduced lung function in adults with obstructive airway disease: an exploratory study. BMJ Open. 2019; 9(1): e024330. PubMed Abstract | Publisher Full Text | Free Full Text

15. Anzai N, Kawabata H, Hirama T, et al:: Types of Nuclear Endonuclease Activity Capable of Inducing Internucleosomal DNA Fragmentation Are Completely Different between Human CD34+ Cells and Their Granulocytic Descendants. Blood. 1995; 86(3): 917-23. PubMed Abstract

16. Jiang $K$, Sun $X$, Chen $Y$, et al.: RNA Sequencing from Human Neutrophils Reveals Distinct Transcriptional Differences Associated with Chronic Inflammatory States. BMC Med Genomics. 2015; 8: 55 PubMed Abstract | Publisher Full Text | Free Full Text

17. Adrover JM, Nicolás-Ávila JA, Hidalgo A: Aging: A Temporal Dimension for Neutrophils. Trends Immunol. 2016; 37(5): 334-45. PubMed Abstract | Publisher Full Text

18. Wright HL, Thomas HB, Moots RJ, et al.: RNA-Seq Reveals Activation of Both Common and Cytokine-Specific Pathways Following Neutrophil Priming.
PLoS One. 2013; 8(3): e58598

PubMed Abstract | Publisher Full Text | Free Full Text

19. Haslett C, Guthrie LA, Kopaniak MM, et al.: Modulation of Multiple Neutrophil Functions by Preparative Methods or Trace Concentrations of Bacterial Lipopolysaccharide. Am J Pathol. 1985; 119(1): 101-110. PubMed Abstract | Free Full Text

20. Chen CM, Lee JA, Yen CF: Improvement in Resolution of Laser Capture Microdissection Using Near-Field Probe to Capture Nanoparticles. IEEE Trans Nanobiosci. 2009; 8(2): 113-19.

PubMed Abstract | Publisher Full Text

21. Kim D, Pertea G, Trapnell C, et al:: TopHat2: Accurate Alignment of Transcriptomes in the Presence of Insertions, Deletions and Gene Fusions. Genome Biol. 2013; 14(4): R36.

PubMed Abstract | Publisher Full Text | Free Full Text

22. Langmead B, Trapnell C, Pop M, et al.: Ultrafast and Memory-Efficient Alignment of Short DNA Sequences to the Human Genome. Genome Biol. 2009; 10(3): R25.

PubMed Abstract | Publisher Full Text | Free Full Text

23. Robinson MD, McCarthy DJ, Smyth GK: EdgeR: A Bioconductor Package for Differential Expression Analysis of Digital Gene Expression Data. Bioinformatics. 2010; 26(1): 139-40.

PubMed Abstract | Publisher Full Text | Free Full Text

24. Zhou Y, Zhou B, Pache L, et al:: Metascape Provides a Biologist-Oriented Resource for the Analysis of Systems-Level Datasets. Nat Commun. 2019; 10(1): 1523.

PubMed Abstract | Publisher Full Text | Free Full Text

25. Livak KJ, Schmittgen TD: Analysis of relative gene expression data using real-time quantitative PCR and the 2(-Delta Delta C(T)) Method. Methods. 2001; 25(4): 402-8.

PubMed Abstract | Publisher Full Text

26. Okutan V, Kürekçi AE, Sarici SU, et al.: Neutrophil Hypersegmentation in Children Receiving Angiotensin Converting Enzyme Inhibitors. TurkJ Pediatr. 2008; 50(5): 438-42.

PubMed Abstract

27. Shrestha S, Noh JM, Kim SY, et al.: Angiotensin Converting Enzyme Inhibitors and Angiotensin II Receptor Antagonist Attenuate Tumor Growth via Polarization of Neutrophils toward an Antitumor Phenotype. Oncoimmunology. 2016; 5(1): e1067744.

PubMed Abstract | Publisher Full Text | Free Full Text

28. Wu YJ, La Pierre DP, Wu J, et al.: The Interaction of Versican with Its Binding Partners. Cell Res. 2005; 15(7): 483-94. PubMed Abstract | Publisher Full Text

29. Wight TN: Versican: A Versatile Extracellular Matrix Proteoglycan in Cell Biology. Curr Opin Cell Biol. 2002; 14(5): 617-23. PubMed Abstract | Publisher Full Text

30. Kang I, Harten IA, Chang MY, et al.: Versican Deficiency Significantly Reduces Lung Inflammatory Response Induced by Polyinosine-Polycytidylic Acid Stimulation. J Biol Chem. 2017; 292(1): 51-63. PubMed Abstract | Publisher Full Text | Free Full Text

31. Domenzain-Reyna C, Hernández D, Miquel-Serra L, et al.: Structure and regulation of the versican promoter: the versican promoter is regulated by AP-1 and TCF transcription factors in invasive human melanoma cells. J Bio Chem. 2009; 284(18): 12306-17. PubMed Abstract | Publisher Full Text | Free Full Text

32. Claushuis TAM, van der Donk LEH, Luitse AL, et al.: Role of Peptidylarginine Deiminase 4 in Neutrophil Extracellular Trap Formation and Host Defense during Klebsiella Pneumoniae-Induced Pneumonia-Derived Sepsis. J Immunol. 2018; 201(4): 1241-1252. PubMed Abstract | Publisher Full Tex

33. Leshner M, Wang S, Lewis C, et al:: PAD4 Mediated Histone Hypercitrullination Induces Heterochromatin Decondensation and Chromatin Unfolding to Form Neutrophil Extracellular Trap-like Structures. Front Immunol. 2012; 3: 307. PubMed Abstract | Publisher Full Text | Free Full Text 
34. Firat-Karalar EN, Welch MD: New Mechanisms and Functions of Actin Nucleation. Curr Opin Cell Biol. 2011; 23(1): 4-13.

PubMed Abstract | Publisher Full Text | Free Full Text

35. Kusunoki $Y$, Nakazawa D, Shida H, et al.: Peptidylarginine Deiminase Inhibitor Suppresses Neutrophil Extracellular Trap Formation and MPO-ANCA Production. Front Immunol. 2016; 7: 227.

PubMed Abstract | Publisher Full Text | Free Full Text

36. Biron BM, Chung CS, O'Brien XM, et al.: Cl-Amidine Prevents Histone 3 Citrullination and Neutrophil Extracellular Trap Formation, and Improves Survival in a Murine Sepsis Model. J Innate Immun. 2017; 9(1): 22-32. PubMed Abstract | Publisher Full Text | Free Full Text

37. $\mathrm{Xu} X$ : Nuclear hypersegmentation of neutrophils, eosinophils, and basophils due to hydroxycarbamide (hydroxyurea). Blood. 2014; 124(9): 1392.

PubMed Abstract | Publisher Full Text | Free Full Text

38. Zhou Y, Chen B, Mittereder N, et al.: Spontaneous Secretion of the Citrullination Enzyme PAD2 and Cell Surface Exposure of PAD4 by Neutrophils. Front Immunol. 2017; 8: 1200. PubMed Abstract | Publisher Full Text | Free Full Text

39. Soehnlein O, Steffens S, Hidalgo A, et al:: Neutrophils as Protagonists and Targets in Chronic Inflammation. Nat Rev Immunol. 2017; 17(4): 248-261. PubMed Abstract | Publisher Full Text

40. Wang $\mathrm{Y}$, Li M, Stadler S, et al:: Histone Hypercitrullination Mediates Chromatin Decondensation and Neutrophil Extracellular Trap Formation. J Cell Biol. 2009; 184(2): 205-13.

PubMed Abstract | Publisher Full Text | Free Full Text

41. Kunisada M, Yogianti F, Sakumi K, et al.: Increased Expression of Versican in the Inflammatory Response to UVB- and Reactive Oxygen Species-Induced Skin Tumorigenesis. Am J Pathol. 2011; 179(6): 3056-65. PubMed Abstract | Publisher Full Text | Free Full Tex
42. Cross NA, Chandrasekharan S, Jokonya N, et al.: The expression and regulation of ADAMTS-1, $-4,-5,-9$, and -15 , and TIMP-3 by TGFbeta 1 in prostate cells: relevance to the accumulation of versican. Prostate. 2005 63(3): 269-75.

PubMed Abstract | Publisher Full Text

43. UniProt Consortium: UniProt: A Worldwide Hub of Protein Knowledge. Nucleic Acids Res. 2019; 47(D1): D506-15. PubMed Abstract | Publisher Full Text | Free Full Text

44. Zhao X, Ting SM, Sun G, et al.: Beneficial Role of Neutrophils through Function of Lactoferrin after Intracerebral Hemorrhage. Stroke. 2018; 49(5): 1241-47.

PubMed Abstract | Publisher Full Text | Free Full Text

45. Hoogendijk AJ, Pourfarzad F, Aarts CEM, et al.: Dynamic TranscriptomeProteome Correlation Networks Reveal Human Myeloid Differentiation and Neutrophil-Specific Programming. Cell Rep. 2019; 29(8): 2505-19.e4. PubMed Abstract | Publisher Full Text

46. Yuda A, Lee WS, Petrovic P, et al.: Novel Proteins That Regulate Cell Extension Formation in Fibroblasts. Exp Cell Res. 2018; 365(1): 85-96. PubMed Abstract | Publisher Full Text

47. Guo X, Wang X, Wang Z, et al.: Site-Specific Proteasome Phosphorylation Controls Cell Proliferation and Tumorigenesis. Nat Cell Biol. 2016; 18(2): 202-12. PubMed Abstract | Publisher Full Text | Free Full Text

48. Lang R, Raffi FAM: Dual-Specificity Phosphatases in Immunity and Infection: An Update. Int J Mol Sci. 2019; 20(11): 2710. PubMed Abstract | Publisher Full Text | Free Full Text

49. Seternes OM, Kidger AM, Keyse SM: Dual-Specificity MAP Kinase Phosphatases in Health and Disease. Biochim Biophys Acta Mol Cell Res. 2019; 1866(1): 124-43.

PubMed Abstract | Publisher Full Text | Free Full Text 


\section{Open Peer Review}

\section{Current Peer Review Status: ? ?}

\section{Version 1}

Reviewer Report 17 January 2022

https://doi.org/10.21956/wellcomeopenres.19285.r47680

(C) 2022 Lokwani R. This is an open access peer review report distributed under the terms of the Creative Commons Attribution License, which permits unrestricted use, distribution, and reproduction in any medium, provided the original work is properly cited.

\section{Ravi Lokwani}

Section on Immuno-Engineering, National Institute of Biomedical Imaging and Bioengineering, National Institutes of Health, Bethesda, MD, USA

The Fox et al, paper on transcriptome of hypersegmented neutrophils provides great insight into the mechanism involves in hypersegmentation of neutrophils and how hypersegmentation is achieved in the laboratory.

In the discussion section and also in the introduction, authors have mentioned previous studies that have reported the presence of hypersegmented neutrophils in a different disease.

I have a few comments that I would like the author to address in the revision of this paper:

1. Are the hypersegmented neutrophils formed after captopril treatment in this study featuring some of the common hypersegmented neutrophil traits that was reported in previous studies i.e. Reduced CD62L expression, High oxidative burst, Increased CD11b expression, etc? I would like the author to carry out a small study to demonstrate these captropil treated hypersegmented neutrophils to validate that these neutrophils feature similar characteristics as hypersegmented neutrophils reported in previous studies. Because if these hypersegmented neutrophils feature similar characteristics as previously reported then it can significantly assist future studies in using this model to to study disease associated hypersegmented neutrophils in more detail.

2. The author had shown that VCAN was dowregulated in hypersegmented neutrophils. Since authors have suggested that VCAN have a role in cellular adheshion, it will be interesting to see if the reduced CD62L expression (one of well known feature of hypersegmented neutrophils) have any association with VCAN. I would like the author to comment on this. Overall, the study is very promising and provides very detailed insight into hypersegmentation of neutrophils.

\section{Is the work clearly and accurately presented and does it cite the current literature?}


Is the study design appropriate and is the work technically sound?

Yes

Are sufficient details of methods and analysis provided to allow replication by others? Yes

If applicable, is the statistical analysis and its interpretation appropriate?

I cannot comment. A qualified statistician is required.

Are all the source data underlying the results available to ensure full reproducibility? Yes

Are the conclusions drawn adequately supported by the results?

Partly

Competing Interests: No competing interests were disclosed.

Reviewer Expertise: Characterizing neutrophil subsets in obstructive airway disease using microscopy and flow-cytometry, Characterizing immune response against biomaterial in mice using flow cytometry.

I confirm that I have read this submission and believe that I have an appropriate level of expertise to confirm that it is of an acceptable scientific standard, however I have significant reservations, as outlined above.

Reviewer Report 07 January 2022

https://doi.org/10.21956/wellcomeopenres.19285.r47678

(C) 2022 Walmsley S. This is an open access peer review report distributed under the terms of the Creative Commons Attribution License, which permits unrestricted use, distribution, and reproduction in any medium, provided the original work is properly cited.

\section{Sarah Walmsley}

Centre for Inflammation Research, Queen's Medical Research Institute, University of Edinburgh, Edinburgh, UK

Fox and colleagues use captopril to induce neutrophil hyper-segmentation and investigate the transcriptional signature of hyper-segmented neutrophils. They identify 5 genes of interest and subsequently explore whether the treatment of neutrophils with the PAD14 inhibitor Cl-amidine can promote neutrophil hyper-segmentation. The manuscript would be considerably strengthened by the authors addressing a number of experimental limitations by providing further clarification of the experimental groups being compared and the provision of additional control data.

1. In general, the number of replicates is extremely limited. Where laser capture microdissection and RNAseq data sets are generated this would be understandable, 
however, the morphological data presented in figure 1 is an $n=3$, and whilst there is limited data variation, this should be highlighted in the results text. With respect to the RNAseq data sets, information regarding $n$ number and biological replicates is currently missing so it is difficult to understand how many replicates were generated for each experimental condition studied.

2. Apologies, but I am unclear as to what data sets are being compared in figure 4. It must be $2 \mathrm{hr}$ hyper-segmented captopril PMN vs another group but I am unsure what that group is, is it baseline PMN, $2 \mathrm{hr}$ normal segmented PMN untreated, or $2 \mathrm{hr}$ normal segmented neutrophils captopril treated. This is important information as it impacts upon the conclusions drawn.

3. How specific is $\mathrm{Cl}$-amidine for PAD14 inhibition, at a minimum, the authors should provide evidence of PAD14 inhibition by $\mathrm{Cl}$-amidine at the concentration studied.

4. Validation of RNAseq data sets is not undertaken in the hyper-segmented PMN population making it difficult to interpret. If the transcriptional signature is specific to the hypersegmented PMN, given they form only a small percentage of the total PMN population in culture even following exposure to captopril, then it would be surprising to see any difference at all in the "whole" PMN population.

5. How does the pathway enrichment analysis relate to the 5 genes of interest.

Conceptually, there are a number of important points that warrant further discussion,

How does a hyper-segmented neutrophil induced by culture with captopril relate to a hypersegmented neutrophil observed in a pathophysiological context?

Why does a transcriptional change in PAD14 implicate NETosis in neutrophil hyper-segmentation. Are the authors proposing that hyper-segmented PMN are cells that fail to NET, or that by inhibiting NETosis cells develop a hyper-segmented phenotype; why is this a small percentage of the total population, is there any evidence that speaks to either of these potential pathways?

Is the work clearly and accurately presented and does it cite the current literature? Partly

Is the study design appropriate and is the work technically sound? Partly

Are sufficient details of methods and analysis provided to allow replication by others? Partly

If applicable, is the statistical analysis and its interpretation appropriate? Partly

Are all the source data underlying the results available to ensure full reproducibility? Partly 
Are the conclusions drawn adequately supported by the results?

Partly

Competing Interests: No competing interests were disclosed.

Reviewer Expertise: neutrophil biology

I confirm that I have read this submission and believe that I have an appropriate level of expertise to confirm that it is of an acceptable scientific standard, however I have significant reservations, as outlined above. 